07;08

\title{
Особенности излучательных свойств квантово-размерных частиц узкозонных полупроводников
}

\author{
() Н.Д. Жуков, С.А. Сергеев, А.А. Хазанов, И.Т. Ягудин
}

Саратовский национальный исследовательский государственный университет им. Н.Г. Чернышевского, Саратов, Россия E-mail: ndzhukov@rambler.ru

Поступило в Редакцию 17 июня 2021г.

В окончательной редакции 30 июля 2021 г.

Принято к публикации 6 августа 2021 г.

Для коллоидных квантово-размерных частиц $(\mathrm{QP})$ узкозонных полупроводников в отличие от квантовых точек широкозонного CdSe имела место аномальная температурная зависимость фотолюминесценции в $\mathrm{QP}-\mathrm{PbS}$, а в планарной микроструктуре QP-InSb наблюдались длинноволновые излучение (более $3 \mu \mathrm{m}$ ) и фотопроводимость (более $20 \mu \mathrm{m}$ ). При определенных условиях интенсивность излучения и сигнал фотопроводимости имеют резонансный максимум. Эффекты объяснены в модели одномерного квантового осциллятора, энергия которого существенно зависит от эффективной массы его квазисвободного электрона. Это приводит к конкуренции проявлений длинноволнового излучения и фотолюминесценции и в связи с этим к аномальной температурной зависимости фотолюминесценции. Предполагается, что QP-InSb в планарной микроструктуре могут быть источниками и приемниками терагерцевого излучения, свойства которых зависят от кристаллической структуры квантово-размерных частиц, определяемой параметрами их синтеза.

Ключевые слова: квантово-размерная частица, квантовая точка, узкозонный полупроводник, эффективная масса, зона Бриллюэна, размерное квантование, квантовый осциллятор, фотолюминесценция, длинноволновое излучение.

DOI: 10.21883/PJTF.2021.22.51725.18927

В последние годы большое число научных публикаций посвящено коллоидным квантовым точкам (QD) в основном с использованием относительно широкозонных полупроводников - халькогенидов кадмия [1]. При этом главной современной тенденцией являются синтез и исследования наноразмерных образований различных форм: полигональные и большие QD, нанонити, нанопластинки, наносвертки и др. [2]. В более ранних работах основная направленность исследований и приложений QD была связана с их излучательным свойством фотолюминесценцией. Разнообразие форм и размеров создает возможности для развития вариантов приложений, в частности, в микро- и наноэлектронике [3].

Квантовая точка является нульмерным физическим объектом. Коллоидные QD - на самом деле трехмерные образования, квантово-размерные частицы (QP). Размеры квантования в них определяются параметрами квантовой модели, в частности длиной волны де Бройля для электрона в полупроводнике $-\Lambda=h(2 m \mathscr{E})^{-1 / 2}$, где $h$ - постоянная Планка, $m$ - эффективная масса электрона, а $\mathscr{E}-$ его кинетическая энергия. Размеры $\mathrm{QP} a_{i}$ должны быть не больше $\Lambda$.

Для квантово-размерной частицы в отличие от квантовой точки принципиальное значение имеют ее кристаллическая структура и анизотропия свойств. Особый интерес при этом представляют узкозонные полупроводники, имеющие высокие значения параметров размерного квантования благодаря специфике зонной структуры. Так, для InSb, для которого характерна экстремально малая величина эффективной массы $m\left(m \sim 0.014 m_{0}\right.$, $m_{0}$ - масса „покоя“ электрона), размер квантования может достигать $60 \mathrm{~nm}$ [4], а для $\mathrm{PbS}\left(m / m_{0} \sim 0.07\right)-$ $25 \mathrm{~nm}$ [5]. В связи с этим QP по сравнению с QD будут иметь особенности свойств, в частности излучательных. Если в QD относительно широкозонных полупроводников, например $\mathrm{CdSe}$, фотолюминесценция определяется экситонной моделью и имеет высокие уровни интенсивности, то для узкозонных, например $\mathrm{InSb}$ и $\mathrm{PbS}$, она многократно слабее и обусловлена другими механизмами [6].

Целью настоящей работы является исследование особенностей излучательных свойств наиболее изучаемых квантово-размерных частиц на основе узкозонных полупроводников: QP-PbS и QP-InSb. QP изготавливались методом коллоидного синтеза [7] и исследовались методами фотолюминесценции [6], просвечивающей электронной микроскопии (TEM) [8] и с помощью анализа вольт-амперных характеристик (BАХ) [9].

Исследования на просвечивающем электронном микроскопе Libra-120 (Carl Zeiss, Германия) показали, что нанокристаллы QP имеют формы с полигональной огранкой (рис. $1, a)$, соответствующие сингонии кристаллической решетки полупроводников. Это должно привести к проявлению обычных для кристаллов свойств, таких как анизотропия, влияние параметров зонной структуры, квантово-размерные эффекты и др.

Измерения размеров наночастиц проводились по ТЕМ-снимкам на случайных выборках при большом увеличении на экране компьютера рядами по 100 частиц подряд. Было установлено, что для случаев медленной 
(квазиравновесной) кристаллизации наблюдалось распределение с двумя максимумами (рис. $1, b$, кривая 1 ). Это может быть связано с неизотропным ростом кристаллитов, определяемым анизотропией термодинамических свойств кристаллической решетки.

В случае распределения по размерам с двумя максимумами для QP-PbS наблюдались два максимума на спектральной кривой фотолюминесценции (рис. 1, $b$, кривая 3). Температурная зависимость интенсивности излучения при этом имела аномальный характер (рис. 2). Для QP-InSb измерения фотолюминесценции не анализировались из-за очень малой интенсивности.

По теории трехмерной квантово-размерной частицы, в модели глубокой протяженной потенциальной ямы и в приближении эффективной массы энергетический спектр разрешенных электронных состояний находится с помощью решения уравнения Шредингера и представляется в виде [10]:

$$
\mathscr{E}_{g l p}=h^{2}(8 m)^{-1}\left(g^{2} a_{x}^{-2}+l^{2} a_{y}^{-2}+p^{2} a_{z}^{-2}\right),
$$

где $g, l, p=1,2,3, \ldots$ - квантовые числа; $a_{x}, a_{y}$, $a_{z}$ - размеры квантовой ячейки вдоль осей $x, y$, $z$ соответственно. Для случая кубической симметрии $\left(a_{x}=a_{y}=a_{z}=a\right)$

$$
\mathscr{E}_{g l p}=3 h^{2}\left(8 m a^{2}\right)^{-1}\left(g^{2}+l^{2}+p^{2}\right) .
$$

Для энергетического уровня невозбужденного состояния $\mathscr{E} 1=3 h^{2}\left(8 m a^{2}\right)^{-1} \approx\left(m / m_{0}\right)^{-1} a^{-2}(\mathscr{E}-[\mathrm{eV}], a-$ $[\mathrm{nm}])$. Рассчитанные по этой формуле спектральные зависимости фотолюминесценции (рис. $1, b$, кривая 2) имеют хорошее совпадение в максимумах при значениях $m / m_{0} \sim 0.07$ для первого максимума и $m / m_{0} \sim 0.1$ для второго. Эти величины $m / m_{0}$ с учетом анизотропии свойств совпадают с известными значениями для пленочного и объемного сульфида свинца $[5,11]$.

При фотолюминесценции электроны возбуждаются квантами большой энергии из валентной зоны в зону проводимости, термализуясь и взаимодействуя с дырками, например образуя экситоны, рекомбинируют, излучая фотоны. В узкозонных полупроводниках из-за высокой подвижности электронов (малых значений $m / m_{0}$ ) вероятность образования экситонов при комнатной температуре пренебрежимо мала. В этом случае необходимы другие варианты возбуждения. Мы использовали вариант эмиссионно-инжекционного механизма в мультизеренной микроструктуре, описанный в наших работах $[12,13]$. Под действием приложенного к микроструктуре поля электрон в возбужденном состоянии претерпевает эмиссию из той или иной QP в нанозазор, а затем - инжекцию в соседнюю QP, в которой он переходит в невозбужденное состояние. Мы предполагаем, что при этом должна излучиться энергия в виде квантов $h v=\mathscr{E}_{i} \approx\left(m / m_{0}\right)^{-1} a_{i}^{-2}$. Например, при $a=5 \mathrm{~nm}$ длина волны излучения должна быть $\sim 3 \mu \mathrm{m}$ для QP-PbS и $\sim 20 \mu \mathrm{m}$ для QP-InSb. В связи с этим
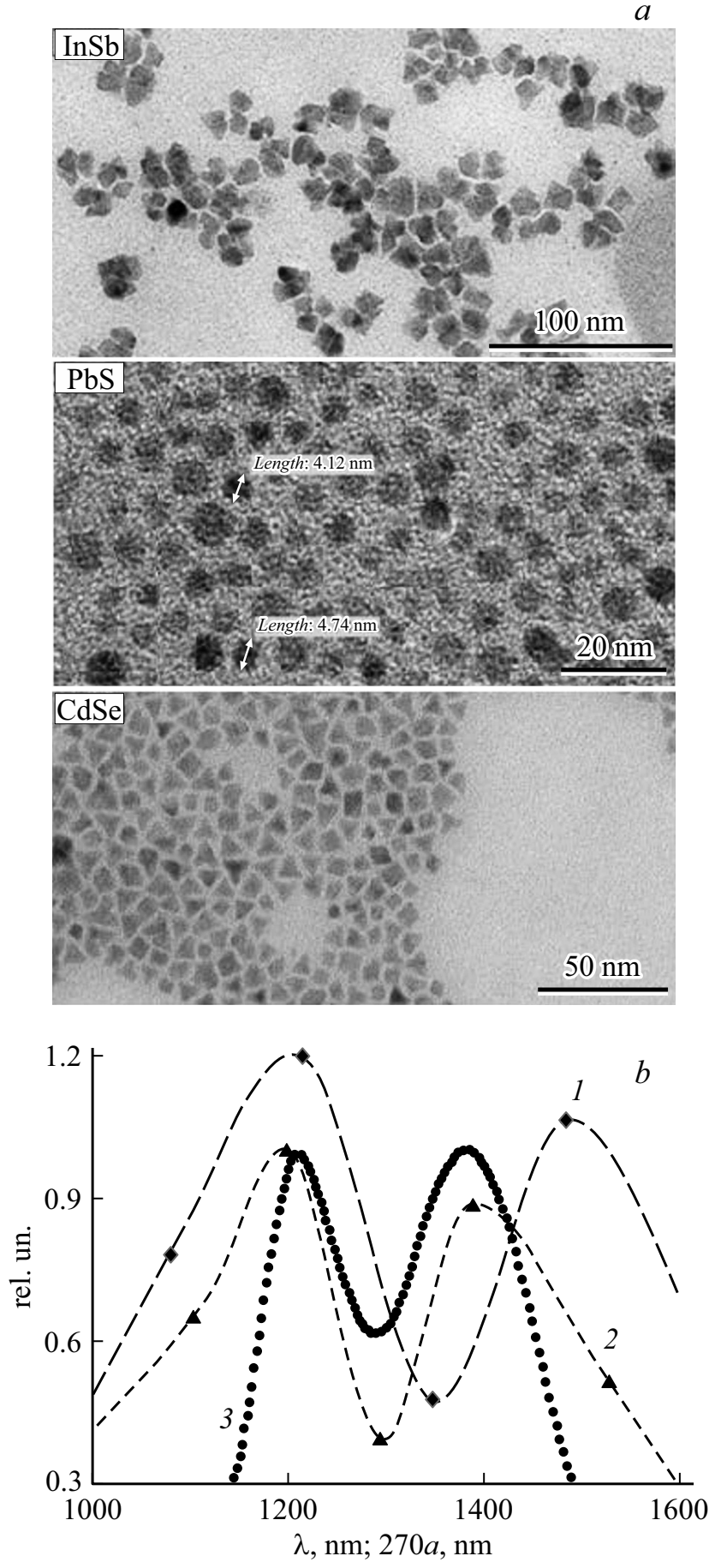

Рис. 1. $a-$ фрагменты TEM-снимков QP-InSb, QP-PbS, а также QD-CdSe из работы [8] (для сравнения); $b-$ экспериментальная (1) зависимость распределения размеров частиц для $\mathrm{QP}-\mathrm{PbS}(270 a$ по оси абсцисс) и спектры фотолюминесценции $(2,3)$ для $\mathrm{QP}-\mathrm{PbS}$ ( $\lambda$ по оси абсцисс).

интересно было получить излучение в длинноволновом (инфракрасном и терагерцевом) диапазоне, для чего использованы QP-InSb c относительно большими размерами, синтезированные и исследованные нами в работе [14]. 


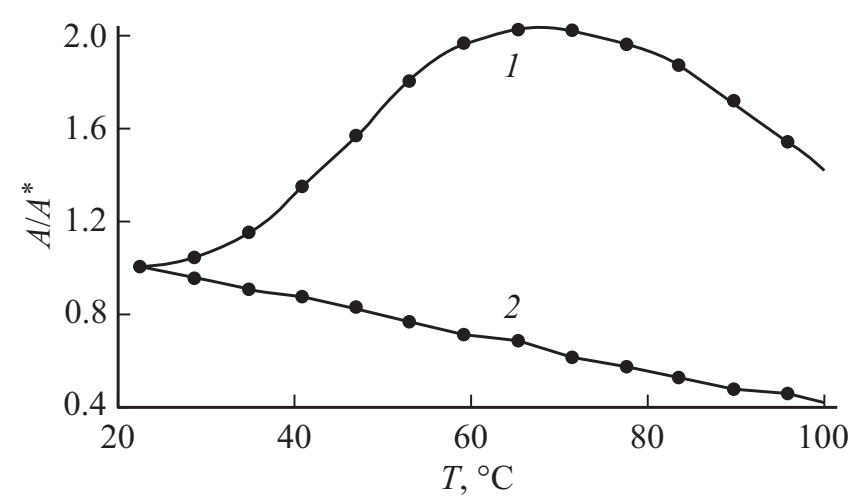

Рис. 2. Температурные зависимости отношения интенсивности $A$ фотолюминесценции в спектральном максимуме к интенсивности $A^{*}$ при температуре $22^{\circ} \mathrm{C}: 1$ - для QP-PbS (аномальная), 2 - для QD-CdSe (нормальная).

Регистрация спектра и интенсивности длинноволнового (терагерцевого) излучения - довольно сложная научно-техническая задача, которой посвящено большое количество исследований [15]. Наибольшие трудности возникают при детектировании слабых сигналов, как в нашем случае. Конструкции фотодетекторов сложны технически и практически малодоступны. Отсутствие излучения в менее длинноволновом диапазоне (до $3 \mu \mathrm{m}$ ) и фотопроводимости (до $20 \mu \mathrm{m}$ ) нами надежно проверялось на спектральном комплексе на базе монохроматора МДР-41 со сменными дифракционными решетками и необходимым подбором источников и фотодетекторов [16].

В том случае, если предложенная нами микроструктура излучает, на основе принципа взаимности она должна на это же излучение и реагировать, т. е. быть адекватным фотоприемником. Нами были проведены соответствующие эксперименты.

Были взяты два одинаковых образца QP-InSb, изготовленных по методу, описанному в нашей работе [13], из которых один выполнял роль излучателя, а другой - приемника. На излучатель подавали постоянное питающее напряжение $V_{=}$, а на приемнике измеряли BAX методом, описанным в [13]. Было обеспечено и проверено отсутствие нежелательного (электрического и емкостного) взаимодействия образцов с гарантией того, что влияние одного на другой могло происходить только благодаря электромагнитному излучению. Была проведена оценка влияния тепловой радиации за счет нагрева излучателя и установлено, что оно в нашем случае пренебрежимо мало.

На рис. 3 представлены результаты измерений ВАХ. При повышении питающего напряжения $V_{=}$на излучателе с 30 до $100 \mathrm{~V}$ наблюдались заметное увеличение тока приемника и его всплеск при напряжении $V_{=}=60 \mathrm{~V}$ (рис. 3,a). Исследования ВАХ в разных координатах (рис. $3, b$ ) с учетом модели одноэлектронного транспорта [10] показали, что лимитирующим его механизмом в структуре приемника QP-InSb для случаев $V_{=}$, равного 30 и $100 \mathrm{~V}$, является ток, ограниченный локализованным в QP зарядом, а для $V_{=}=60 \mathrm{~V}$ - эмиссия из QP. Это может означать, что при относительно слабом воздействии в структуре приемника ограничивают процесс транспорта инжектированных и термализуемых в QP электронов, а при более сильном - процесс эмиссии в межзеренные нанозазоры.

Особенность QP с совершенной кристаллической структурой проявляется в том, что квантуется не только энергия, но и импульс электрона, т.е. его движение происходит в порядке, определяемом свойствами зоны Бриллюэна. В этом случае можно принять, что резонансное движение электрона в QP линейно, и применить модель одномерного гармонического осциллятора [17].

Резкое возрастание тока приемника для случая напряжения $V_{=}=60 \mathrm{~V}$ (рис. 3, $a$ ) мы объясняем увеличением интенсивности излучения за счет возможного энерге-
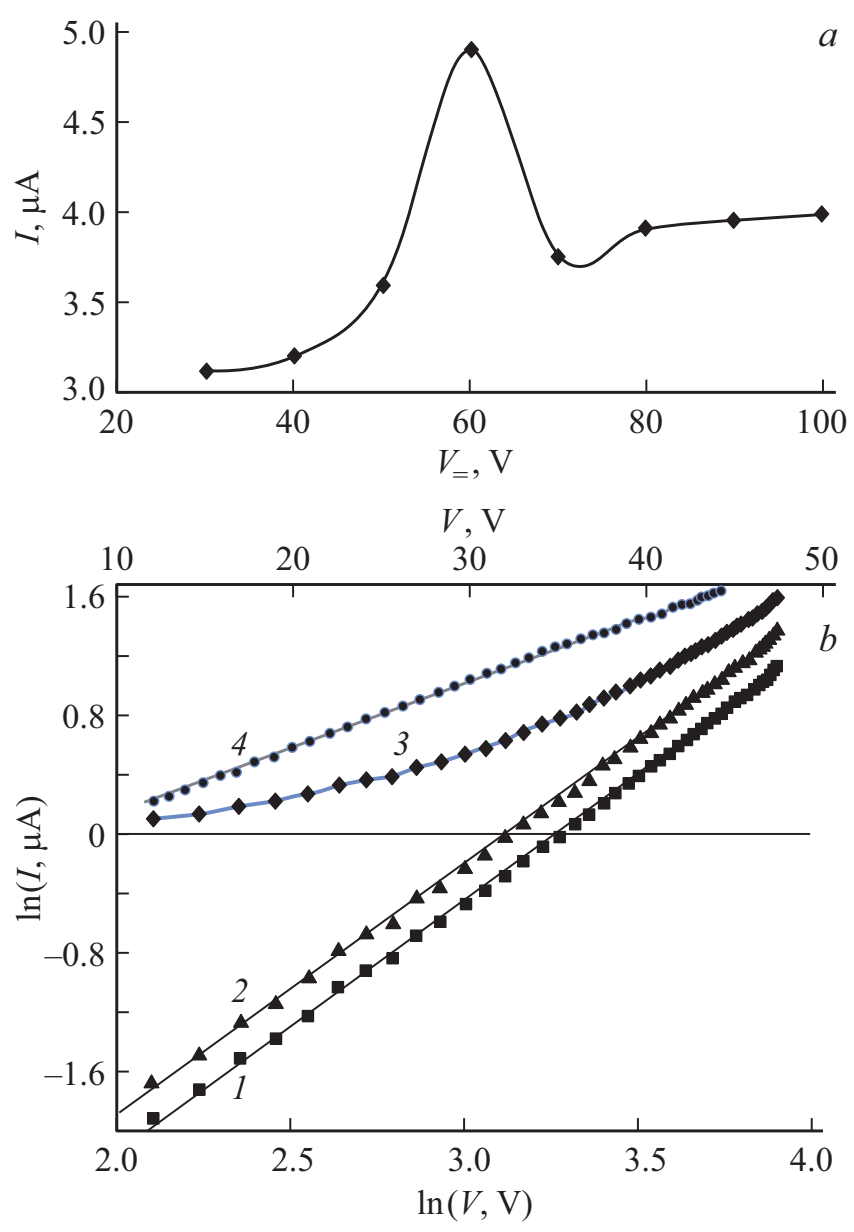

Рис. 3. $a-$ зависимость тока приемника при $V=50 \mathrm{~V}$ от напряжения $V=$ на излучателе; $b-\mathrm{BAX}$ приемника при различных значениях $V=$ (в скобках указаны параметры линейной аппроксимации) в координатах $\ln I \sim \ln V: 1-$ $V_{=}=30 \mathrm{~V}\left(y=1.693 x-5.513, R^{2}=0.997\right), 2-V_{=}=100 \mathrm{~V}$ $\left(y=1.693 x-5.265, R^{2}=0.997\right), 3-V_{=}=60 \mathrm{~V}$, а также в координатах $\ln I \sim V: 4-V_{=}=60 \mathrm{~V}(y=0.036 x-0.181$, $\left.R^{2}=0.999\right)$. 
тического перехода квантового осциллятора на первый резонансный уровень $(n=1)$. По формуле энергии квантового осциллятора $\mathscr{E}=\mathscr{E}_{0}(n+1 / 2)[17]$ интенсивность излучения (в нашем случае тока приемника) должна возрасти примерно в 1.5 раза, что и наблюдается на pис. 3, $a$ : отношение величин тока для случаев $V_{=}=60$ и $30 \mathrm{~V}$ равно $\sim 5: 3$.

Изготовленные и проверенные нами структуры с $\mathrm{QD}-\mathrm{CdSe}$ и QP-PbS не проявляли обсуждаемого эффекта длинноволновых излучения и фотопроводимости.

Таким образом, в представлении квантово-размерной частицы как квантового осциллятора благодаря разнице важнейшего свойства электронов, характеризующего их подвижность, - эффективной массы $m / m_{0}-$ в QP-InSb, имеющих самые малые значения $m / m_{0}(\sim 0.014)$, в отличие от QD-CdSe $\left(m / m_{0} \sim 0.15\right)$ проявляется длинноволновое излучение, но отсутствует фотолюминесценция. Для QP-PbS, имеющих промежуточное значение параметра $m / m_{0} \sim 0.07$, оба эффекта (длинноволновые излучение и фотопроводимость) проявляются плохо, хотя фотолюминесценция несколько лучше. При этом наблюдается аномальная температурная зависимость, которую мы объясняем конкурирующим влиянием квантоворазмерного и экситонного механизмов. При продолжении исследований для усиления длинноволнового излучения и его регистрации должны быть проведены оптимизация структуры QP и спектральные измерения непосредственно в терагерцевом диапазоне.

\section{Благодарности}

Авторы благодарны А.Г. Рокаху за полезные советы.

\section{Финансирование работы}

Исследование выполнено при финансовой поддержке Российского фонда фундаментальных исследований в рамках научного проекта 20-07-00603-а.

\section{Конфликт интересов}

Авторы заявляют, что у них нет конфликта интересов.

\section{Список литературы}

[1] M. Alizadeh-Ghodsi, M. Pourhassan-Moghaddam, A. ZavariNematabad, B. Walker, N. Annabi, A. Akbarzadeh, Part. Part. Syst. Charact., 36 (2), 180030 (2019). DOI: $10.1002 /$ ppsc.201800302

[2] D. Porotnikov, M. Zamkov, J. Phys. Chem. C, 124 (40), 21895 (2020). DOI: $10.1021 /$ acs.jpcc.0c06868

[3] N. Sitapure, N. Varadan, S. Malani, P. Goswami, M.A.K. Kerawalla, Int. J. Adv. Res. Eng. Appl. Sci., 5 (6), 29 (2016). https://garph.co.uk/IJAREAS/June2016/3.pdf

[4] S. Tamang, K. Kim, H. Choi, Y. Kim, S. Jeong, Dalton Trans., 44 (38), 16923 (2015). DOI: 10.1039/c5dt02181b
[5] С.И. Садовников, Н.С. Кожевникова, А.А. Ремпель, ФТП, 44 (10), 1394 (2010). http://journals.ioffe.ru/articles/viewPDF/7252

[6] Н.Д. Жуков, Д.В. Крыльский, М.И. Шишкин, А.А. Хазанов, ФТП, 53 (8), 1103 (2019). DOI: $10.21883 /$ FTP.2019.08.48002.9037

[7] Д.В. Крыльский, Н.Д. Жуков, Письма в ЖТФ, 45 (16), 10 (2019). DOI: 10.21883/PJTF.2019.16.48147.17665

[8] А.В. Кацаба, В.В. Федянин, С.А. Амброзевич, А.Г. Витухновский, А.Н. Лобанов, А.С. Селюков, Р.Б. Васильев, И.Г. Саматов, П.Н. Брунков, ФТП, 47 (10), 1339 (2013). http://journals.ioffe.ru/articles/viewPDF/5094

[9] Н.Д. Жуков, М.В. Гавриков, Д.В. Крыльский, Письма в ЖТФ, 46 (17), 47 (2020). DOI: 10.21883/PJTF.2020.17.49895.18355

[10] В.П. Драгунов, И.Г. Неизвестный, В.А. Гридчин, Основы наноэлектроники (Логос, М., 2006).

[11] Е.В. Мараева, Получение и исследование наноструктурированных поликристаллических слоев и систем с квантовыми точками на основе халькогенидов свинца, канд. дис. (СПбГЭТУ „ЛЭТИ“), СПб., 2014).

[12] Н.Д. Жуков, В.Ф. Кабанов, А.И. Михайлов, Д.С. Мосияш, А.А. Хазанов, М.И. Шишкин, ФТП, 52 (1), 83 (2018). DOI: 10.21883/FTP.2018.01.45323.8515

[13] Н.Д. Жуков, И.Т. Ягудин, Н.П. Абаньшин, Д.С. Мосияш, Письма в ЖТФ, 46 (21), 40 (2020). DOI: 10.21883/PJTF.2020.21.50196.18392

[14] Д.В. Крыльский, Н.Д. Жуков, Письма в ЖТФ, 46 (18), 15 (2020). DOI: 10.21883/PJTF.2020.18.49995.18358

[15] И.С. Гибин, П.Е. Котляр, Успехи прикладной физики, 6 (2), 117 (2018). http://advance.orion-ir.ru/UPF-18/2/UPF-6-2117.pdf

[16] Н.Д. Жуков, М.И. Шишкин, А.Г. Роках, Письма в ЖТФ, 44 (8), 102 (2018). DOI: 10.21883/PJTF.2018.08.45973.17010

[17] Л.К. Мартинсон, Е.В. Смирнов. Квантовая физика [Электронный pecypc]. URL: http://fn.bmstu.ru/dataphysics/library/physbook/tom5/ch4/texthtml/ch4_5.htm 